УДК

\title{
КОНСТРУКЦИИ МНОГОБИТНОГО СИГМА-ДЕЛЬТА МОДУЛЯТОРА
}

\author{
СОНИКА $^{1}$, НЕЕМА Д.Д. ${ }^{2}$, ПАТЕЛ Р.Н. ${ }^{3}$ \\ ${ }^{1}$ Технологический институт Чхатрапати Шиваджи, \\ Индия, Дург, 491001 \\ ${ }^{2}$ Чхаттисгархский технологический институт, \\ Индия, Раджнандгаон, 495683 \\ ${ }^{3}$ Инженерно-технологический факультет SSGI, \\ Индия, Бхилаи, 490020
}

\begin{abstract}
Аннотация. В статье представлены две конструкции многобитных сигма-дельта модуляторов (СДМ) третьего порядка: СДМ с малым искажением и каскадный СДМ. В основе предложенного каскадного модулятора лежит традиционная конструкция СДМ, например L-0 MASH (Multi-stAge noise SHaping, многокаскадное формирование спектра шума) с межкаскадными обратными связями. СДМ типа MASH не является одноконтурной системой. Одним из недостатков такого устройства является ограничение производительности из-за явления неустранимого шума, распространяющегося от первого модулятора, т.к. межкаскадная обратная связь устраняет только нелинейные ошибки, вносимые многобитным ЦАП в последнем каскаде, в то время как в остальных каскадах по-прежнему возникают ошибки нелинейности ЦАП без формирования шума, что также снижает производительность всей системы. В данной статье предлагается улучшенная версия каскадного многобитного СДМ с устранением указанных проблем. Кроме того предложен СДМ третьего порядка с малыми искажениями. Результаты компьютерного моделирования подтверждают преимущества обоих предложенных модуляторов.
\end{abstract}

Ключевые слова: аналогово-цифровой преобразователь; АЦП; сигма-дельта модулятор; генерация шума; MASH; отношение сигнал/помеха + искажение; коэффициент передискретизации

\section{1. ВВЕДЕНИЕ}

Дельта-сигма аналогово-цифровой преобразователь (АЦП), основанный на передискретизации и формировании шума является наиболее подходящим устройством для систем высокого разрешения с относительно узкой полосой пропускания на средних частотах.

Для получения высокого разрешения в АЦП с передискретизацией (oversampling) необходимо или увеличить частоту дискретизации или модулятор должен обеспечивать более эффективное формирование шума (noise shapi$\mathrm{ng}$ ). В первом случае это приводит к увеличению потребляемой мощности, во втором - возможно появление нестабильности. С другой стороны, возможно увеличить число квантируемых бит, что в свою очередь приводит к уменьшению уровней квантования и уменьшению полосы пропускания и шумов квантования, и как следствие, к увеличению отношения сигнал-шум (ОСШ) и улучшению стабильности, что уменьшает требования к передискретизации [1]. Существенным недостатком многобитных систем является необходимость формирования идеальной интегральной линейности.

В одноконтурных дельта-сигма модулятоpax (СДМ) ошибка, которая появляется в связи с нелинейностью многобитного цифро-анало- 